\title{
Alberto Nepomuceno e o exercício profissional da música
}

Mónica Vermes'

(Universidade Federal do Espírito Santo)

\begin{abstract}
Resumo
Este artigo trata das atividades profissionais de Alberto Nepomuceno (1864-1920) no Rio de Janeiro, no período de 1895 a 1920, desde sua instalação definitiva na cidade após a viagem de estudos à Europa até sua morte. Observamos os vários espaços do exercício profissional da música e a forma como Nepomuceno se situou nesses espaços e como contribuiu para transformá-los.
\end{abstract}

Palavras-chave: Alberto Nepomuceno; música no Rio de Janeiro; músico profissional.

\footnotetext{
${ }^{1}$ Professora da Universidade Federal do Espírito Santo, onde leciona as disciplinas de história da música. Tem experiência na área de Artes, com ênfase em Musicologia, atuando principalmente nos seguintes temas: música brasileira dos séculos XIX e XX. Alberto Nepomuceno, romantismo musical, cenário musical do Rio de Janeiro entre o final do século XIX e início do século XX e cenário musical de Vitória - ES nos séculos XX e XXI. Coordena o Núcleo de Estudos Musicológicos na Universidade Federal do Espírito Santo, orientando alunos de Iniciação Científica. Faz parte do corpo docente do Programa de Pós-Graduação em Artes - Centro de Artes/UFES e do Programa de Pós-Graduação em Letras - CCHN/UFES.
} 


\section{Introdução}

Quando Alberto Nepomuceno mudou-se inicialmente para o Rio de Janeiro em 1885, o fez em busca de melhores oportunidades profissionais: a possibilidade de encontrar apoio para dar prosseguimento a seus estudos na Europa e um ambiente mais propício para o exercício da música. Aos vinte e um anos, Nepomuceno já havia atuado em Fortaleza e em Recife como violinista, professor de matérias teóricas e piano e já havia sido diretor de uma associação musical, o Club Carlos Gomes. Antes de partir para o Rio de Janeiro, havia tentado obter apoio para aprimorar seus estudos no exterior, sem sucesso.

Passados três anos na capital do Império, partiu para estudar na Europa, ainda sem apoio oficial, mas contando com o auxílio de amigos e com os fundos arrecadados através de recitais. Quando volta, em 1895, agora à República Federativa dos Estados Unidos do Brasil, haviam ocorrido algumas transformações na configuração do meio musical carioca, em função da proclamação da república e da "dança das cadeiras" numa das mais importantes instituições musicais do 8 país, o Instituto Nacional de Música, antigo Conservatório Imperial de Música. ${ }^{2}$ Parte significativa da carreira de Nepomuceno se desenvolveu no âmbito dessa instituição, onde exerceu a docência e da qual foi diretor em duas ocasiões. Mas, para além do Instituto, Nepomuceno desempenhou uma variedade de atividades profissionais.

As apresentações de Nepomuceno na historiografia costumam ser plurais: compositor, pianista, organista, regente, professor de composição e de órgão, administrador, polemista, agitador cultural. Essa multiplicidade, no entanto, não chega a minimizar uma tendência a considerá-lo como primordialmente compositor, que exerce outras atividades paralelas. Atividade nobre, do espírito, dissociada das preocupações vulgares do dia-a-dia, mas que não libera o compositor das obrigações menos nobres, mais materiais e prosaicas.

${ }^{2}$ O Conservatório Imperial de Música foi criado por decreto de 1841 pela ação de Francisco Manuel da Silva (1795-1865), compositor, regente, violoncelista, professor, criador do Hino Nacional Brasileiro. Com a proclamação da república, o Conservatório é transformado em Instituto Nacional de Música, hoje Escola de Música da UFRJ. 
Essa versatilidade de Nepomuceno, necessária para assegurar as condições materiais de sobrevivência e para a construção e defesa de um projeto estético e político no âmbito musical, ${ }^{3}$ tornou-se um alvo de críticas de seus detratores, como podemos observar nesta passagem de Oscar Guanabarino: ${ }^{4}$

Quer nos parecer que o fracasso da carreira artística [d]o talentoso cearense, dotado de força de vontade, como atesta a sua resolução, [...] quando muito jovem, de vir para esta Capital sem dispor dos necessários recursos, a ponto de sofrer muitas privações, quer nos parecer, dizíamos, que o seu fracasso foi motivado pelo desejo de adotar várias especialidades a um tempo organista, regente de orquestra, pianista e compositor. Não se especializou em nenhuma dessas atividades e cada uma delas se incumbia de prejudicar as outras.[...] Alberto Nepomuceno foi forçado a dar lições de piano, atividade essa que distrai todas as energias de um artista. E de fato, passou a ser compositor nas horas vagas, nas horas destinadas ao descanso e, daí, a imperfeição de seu trabalho. (Guanabarino, 1920)

Nessa passagem, extraída do necrológio publicado no Jornal do Commercio no dia seguinte ao da morte do compositor, o crítico - um dos mais fiéis adversários de Nepomuceno - emprega sua tradicional ironia, ainda que suavizada pelas circunstâncias. Mas suscita uma importante questão: não se dividindo em várias atividades, qual seria a fonte de sustento de um compositor de música erudita 5 no Rio de Janeiro da República Velha?

Essa questão pode ser desdobrada em outras: o que caracteriza a ação de um músico profissional? O simples fato de sua atividade ser remunerada? A questão não era tão simples, uma vez que gêneros musicais populares, muitas vezes associados a espetáculos teatrais ligeiros - teatro musical, revistas, operetas - poderiam assegurar as condições de sobrevivência ao compositor e aos músicos, devido ao amplo afluxo de público a esse tipo de espetáculo. Mas

\footnotetext{
3 Sobre o projeto estético-político de Nepomuceno e do grupo em torno do Instituto Nacional de Música, ver Pereira, Avelino Romero. Música, sociedade e política: Alberto Nepomuceno e a República Musical. Rio de Janeiro: Editora UFRJ, 2007.

${ }^{4}$ Oscar Guanabarino (1851-1937), pianista, compositor e crítico musical (nesta e em todas as outras qualificações profissionais que apresento neste trabalho, baseio-me nos dados encontrados na Enciclopédia da Música Brasileira). Ele foi um dos principais adversários de Nepomuceno, com quem manteve polêmicas nos jornais.

${ }^{5}$ Optamos por usar a expressão "música erudita" no mesmo sentido em que se costuma usar "música clássica" ou "música de concerto". Entendemos que cada uma dessas expressões é problemática e limitada.
} 
tais atividades eram vistas com desprezo por aqueles que se dedicavam à música erudita.

No intuito de entender como se dava o exercício profissional da música no Rio de Janeiro, observamos os espaços em que essas atividades eram desempenhadas e a forma como Nepomuceno se relacionou com esse meio e o transformou. Tratamos do período que vai de 1895 (ano em que Nepomuceno se estabeleceu em definitivo no Rio depois do retorno de sua viagem de estudos à Europa) até 1920 (ano de sua morte). Vários aspectos são tratados em separado: teatros, orquestras e sociedades de concertos, repertórios, músicos e instituições de ensino. Em seguida, analisamos de que forma Nepomuceno se situou nesse meio, interferindo nele. Mais do que isso, projetando um plano de ação que visava a transformar esse cenário musical.

\section{Teatros e Repertórios}

Um dos principais espaços para exercício da atividade musical eram os teatros, e havia vários deles no Rio de Janeiro no período em tela. A partir de um cruzamento das informações encontradas no Guia de Teatros do Centro Histórico do Rio de Janeiro, ${ }^{6}$ com as informações sobre músicos e atividades musicais encontradas no livro Storia della musica nel Brasile de Vincenzo Cernicchiaro (1926), ${ }^{7}$ em 150 anos de música no Brasil de Luiz Heitor Corrêa de Azevedo (1956) e um levantamento na programação dos teatros publicada na seção "Diversões" do jornal O Paiz, complementamos e refinamos a caracterização dos principais teatros em atividade no Rio de Janeiro dessa época que já havíamos começado a esboçar em trabalho anterior (Vermes, 2006, p. 112-121).

Entre os principais teatros do Rio do período destacam-se:

\footnotetext{
${ }^{6}$ Disponível no endereço <http://www.ctac.gov.br/centrohistorico/apresentacao.asp >.

7 É amplamente reconhecido o fato de existirem várias imprecisões na obra de Cernicchiaro, além de suas opiniões serem fortemente marcadas por simpatias e antipatias estéticas e pessoais. O emprego que fazemos aqui de sua obra é como testemunho de alguém que viveu essa época da vida musical do Rio de Janeiro, mérito também amplamente reconhecido.
} 
- Teatro Eden-Lavradio, inaugurado em 1895, teve as atividades interrompidas em 1899. Situado à rua do Lavradio, 96, o edifício hoje abriga uma escola. ${ }^{8}$ A programação do Eden-Lavradio compreendia subgêneros operísticos mais ligeiros, como óperas cômicas, óperas cômico-fantásticas, e revistas. ${ }^{9}$

- Teatro Apolo, inaugurado em 1890, teve as atividades extintas pela morte do proprietário em 1916. Situado à rua do Lavradio, 50. A programação do Apolo compreendia óperas cômicas, operetas, revistas e comédias e seria o "preferido das companhias portuguesas de revistas e operetas"10. Luiz Heitor identifica o Apolo (junto com Lírico e o São Pedro de Alcântara) como um dos teatros que recebiam companhias de ópera nos primeiros anos do século $X X$ (Azevedo, 1956, p. 203).

- Teatro São Pedro de Alcântara, funcionou entre 1857 e 1916. Em 1916 passou por uma importante remodelação e foi reinaugurado, mantendo-se em atividade com esse mesmo nome até 1923, quando passou a chamar-se Teatro João Caetano. Situado na praça da Constituição (atual praça Tiradentes). A programação do São Pedro de Alcântara incluía espetáculos de clowns, musicais e óperas, recebeu também concertos sinfônicos.

- Teatro Fênix Dramática, funcionou na rua da Ajuda, 57 de 1868 a 1905. ocasião em que foi demolido para dar lugar à av. Central (atual av. Rio Branco). Foi reinaugurado em 1910 ou 1916 para funcionar como cinema e music hall. Esse teatro foi dirigido desde 1869 por Henrique Alves de Mesquita, ${ }^{11}$ que lá apresentaria suas “operetas sincopadas” (Machado, 2010, p. 131).

- Teatro Lírico (antes Teatro Imperial D. Pedro II), funcionou de 1890 a 1934 na rua da Guarda Velha (atual rua Treze de Maio), 10. Foi demolido. Luiz Heitor noticia a estreia da ópera Jupira de Francisco Braga nesse teatro em 1900

\footnotetext{
${ }^{8}$ As informações relativas a ano de inauguração, ano de encerramento das atividades, motivo de encerramento das atividades e endéreço, salvo indicação em contrário, foram tomadas do Guia de Teatros do Centro Histórico do Rio de Janeiro (ver nota 5 acima).

${ }^{9}$ Revista, ou teatro de revista, é um "gênero de teatro musicado caracterizado por passar em revista os principais acontecimentos do ano, encenando-os em uma sucessão de quadros em que os fatos são revividos com intenção de humor, em meio a danças, canções e outros números musicais" (verbete "Teatro de Revista" da Enciclopédia da música brasileira)

${ }^{10}$ Ver "Theatro Apollo (1890)" no Guia de Teatros do Centro Histórico do Rio de Janeiro.

${ }^{11}$ Henrique Alves de Mesquita (1830-1906), compositor, organista, regente e professor.
} 
(Azevedo, 1956, p. 184). Sua programação era variada, recebia zarzuelas, operetas e peças teatrais.

- Concerto Avenida do Pavilhão Internacional, que funcionou de 1908 a 1911 com essa denominação e em 1911 adota o nome Cinema-Theatro do Pavilhão Internacional. Situado na av. Central (av. Rio Branco). Programação variada, que incluía canto, dança, acrobacias e lutas de boxe.

- Teatro Sant'Anna, que funcionou entre 1880 e 1905 na rua Luiz Gama, praça da Constituição (atual praça Tiradentes). Em 1905 foi reinaugurado como Teatro Carlos Gomes e desapareceu em 1929 devido a um incêndio. Sua programação compreendia operetas, revistas e peças teatrais.

- Teatro Lucinda, em atividade entre 1884 e 1909, na rua do Espírito Santo, 24, nos arredores da praça Tiradentes. Apresentação de comédias, revistas e peças teatrais. Luiz Heitor menciona a realização de uma série de concertos por Francisco Braga nesse teatro (Azevedo, 1956, p. 184).

- Teatro Municipal do Rio de Janeiro, inaugurado em 1909. Segundo Luiz Heitor, ele surge como "complemento à remodelação da capital brasileira que o grande prefeito Pereira Passos ia convertendo numa cidade moderna" e, a partir

12 daí, haveria uma significativa transformação nas temporadas de ópera do Rio (Azevedo, 1956, 209-10).

Além dos teatros listados acima, podemos mencionar também o Cassino Palace (1906), o Teatro Cassino Nacional (1902-1906), o Cinematógrafo Pathé (1915), o Teatro Vitória (1918-1919), o Teatro Variedades Dramáticas (18881900), o Café-Cantante Moulin Rouge (1900-1903), o Teatro Chantecler (19111913), o Cinema-Teatro Rio Branco (1911-1915) e o Teatro da Natureza (1916).

Além dos teatros, as salas de cinemas e confeitarias que mantinham orquestras eram também espaço de trabalho para os músicos. Villa-Lobos, ${ }^{12}$ como é frequentemente lembrado, manteve-se durante muito tempo tocando em "cinemas, orquestras de teatros, confeitarias" ou "orquestrinhas de salão" (Azevedo, 1956, p. 252, 254, 277).

\footnotetext{
${ }^{12}$ Heitor Villa-Lobos (1887-1959), compositor, regente, professor.
} 


\section{Repertórios e Gêneros Musicais}

Observando o panorama geral dos teatros cariocas que apresentamos acima, é possível notar que, tipicamente, a programação dos teatros cariocas incluía espetáculos musicais. Tanto assim a ponto de gerar desconforto na classe teatral. Lemos na coluna "Teatros e Música" do Jornal do Commercio de 16 de março de $1895:^{13}$

Pode-se assegurar que há muitos anos não temos arte dramática e apenas um ou outro representante que faz recordar os bons tempos em que em nossos teatros apareciam artistas dignos desse nome. Dizem alguns que a culpa desse desaparecimento viria da imprensa que não compreende a sua missão em matéria teatral, outros que a culpa é do público que foge do teatro quando se anunciam drama ou mesmo comédias em que não há fados, tangos e outros excitantes [...]

A presença abundante de música na programação teatral se concentra nos gêneros musicais mais ligeiros e populares - revistas, operetas, burletas - que foram se distanciando e polarizando da produção mais erudita, artística, calcada na música instrumental europeia principalmente de tradição germânica. Segundo Luiz Heitor, de 1870 em diante observa-se "um curioso fenômeno de divergência entre a orientação dos compositores de escola, com obras cantadas ou executadas nos salões da boa sociedade, e a desses compositores populares" (Azevedo, 1956, p. 137-38).

É possível apreender de observações deixadas por músicos de formação acadêmica a ideia de uma diferenciação entre duas categorias de músicos baseadas em princípios não só de natureza estética, mas também de natureza social e até mesmo ética. Essa diferenciação parecia gerar uma expectativa de tratamento diferenciado. Mas a realidade da atividade musical não parecia seguir tais expectativas. Observemos a carta enviada pelo compositor baiano Silvio Deolindo Fróis ${ }^{14}$ a Alberto Nepomuceno em 20 de agosto de 1919:

\footnotetext{
${ }^{13}$ Essa coluna aparece sem assinatura. Já tratamos desse comentário em trabalho anterior, ver Vermes, Mónica (2004).

${ }^{14}$ Sílvio Deolindo Fróis (1865-1948), compositor, pianista, organista, professor e crítico.
} 
Sempre fico imbuído da convicção de que este país não é terreno musical de certa ordem. O fato de haver um Nepomuceno, um Oswaldo, ${ }^{15}$ um F. Braga, ${ }^{16}$ um Miguez, ${ }^{17}$ um Carlos Gomes ${ }^{18}$ e outros não é capaz de dar desenvolvimento à cultura musical do povo. Daqui a alguns lustros Vs. também serão dos rari nantes [náufragos no imenso mar]. ${ }^{19}$ Basta citar que o elemento oficial no nosso país presta mais atenção, dá mais importância a um autor de opereta do que a um sinfonista.

Essa polarização da atividade musical entre uma música de alta cultura e uma música de apelo mais popular terá consequências importantes na subsistência dos músicos. Os concertos de música erudita eram menos numerosos e atraíam um público menor, particularmente os concertos de música instrumental e as récitas de ópera organizados com músicos locais. Estes viam-se então obrigados a trabalhar nas orquestras de espetáculos populares, nos cafés e nas salas de cinema para poder assegurar o sustento.

\section{Orquestras e sociedades de concertos}

A realização de concertos de música sinfônica e de câmara vai passar por um incremento significativo ao longo do século XIX. Num ambiente fortemente marcado pela presença da ópera italiana, a atividade das sociedades musicais ampliará o repertório, do público e dos músicos.

Uma das pioneiras foi a Sociedade Filarmônica, posteriormente Sociedade Musical Campesina (1834-1880) à qual esteve ligado Francisco Manuel da Silva. Outras sociedades dessa natureza foram o Clube Mozart (fundado em 1867), no qual John Jesse White ${ }^{20}$ teve um papel de destaque; o Clube Beethoven (18821889), fundado por Robert Jope Kinsman Benjamin; ${ }^{21}$ a Sociedade de Concertos Clássicos (fundada em 1883) de José White ${ }^{22}$ e Artur Napoleão. ${ }^{23}$ Os concertos

\footnotetext{
${ }^{15}$ Henrique Oswald (1852-1931), compositor, pianista e professor.

${ }^{16}$ Francisco Braga (1868-1945), compositor, regente e professor.

${ }^{17}$ Leopoldo Miguez (1850-1902), compositor, regente, violinista e professor.

${ }^{18}$ Antônio Carlos Gomes (1836-1896), compositor e regente.

${ }^{19}$ Fróis faz aqui referência a uma passagem da Eneida de Virgílio (I, 118).

20 John Jesse White, violinista, compositor e regente inglês.

${ }^{21}$ Robert Jope Kinsman Benjamin (1853-1927), violinista, regente, crítico, professor e compositor.

22 José White (1836-1918), violinista e compositor cubano.

${ }^{23}$ Artur Napoleão (1843-1925), pianista, professor e compositor português.
} 
realizados por essas associações, no entanto, eram destinados aos associados. A primeira temporada de concertos sinfônicos públicos realizada no Rio de Janeiro teve lugar em 1887 pela Sociedade de Concertos Populares, fundada nesse ano por Carlos de Mesquita. ${ }^{24}$

Juntam-se a essas outras iniciativas posteriores, como a Associação de Concertos Populares (1896-1897), dirigida por Alberto Nepomuceno; o Centro Artístico (fundado em 1893), uma iniciativa mais ampla, que reuniu Leopoldo Miguez, Alberto Nepomuceno, Luís de Castro e Coelho Neto:25 o Clube Sinfônico de Amadores, de Ciríaco Cardoso ${ }^{26}$ e no qual Leopoldo Miguez era regente substituto.

Já entrado o século XX, encontramos a Sociedade de Concertos Sinfônicos do Rio de Janeiro (1912-1932) fundada por Francisco Nunes, ${ }^{27}$ orquestra que fica cerca de vinte anos sob a regência de Francisco Braga.

Sem funcionamento contínuo e sem a possibilidade de contratar os músicos em regime de exclusividade, essas orquestras se ressentiam, e aparentemente isso era evidente no resultado musical, de ter que dividir os músicos, que, para assegurar o sustento, trabalhavam também nas orquestras populares. Há vários testemunhos, que apresentamos abaixo, que identificam essa questão como um dos elementos que dificultam o desenvolvimento de um meio musical mais plenamente desenvolvido no Brasil.

Silvio Deolindo Fróis comenta na mesma carta a Alberto Nepomuceno que já citamos anteriormente:

Entretanto quando, mui poucas vezes, arrisquei concertos sinfônicos na Bahia, ensaiados durante um ano ou mais, 3 vezes por semana ao menos, de sorte que os músicos, a força dessa ingente martelagem, conseguissem quase automaticamente, certas nuances indispensáveis e mesmo vencer essas insignificantes dificuldades de divisão de compasso e de uma ou outra passagem menos corrente; nessas poucas vezes em que, após um trabalho que, pela sua imensidade, toca visivelmente ao ridículo; [...] tudo isso, toda essa incrível soma de esforços tem-me apenas rendido desgostos; mais do que acarretou despesas do meu bolso próprio. (Fróis, carta de 20 ago. 1919)

\footnotetext{
${ }^{24}$ Carlos de Mesquita (1864-1953), compositor, pianista, organista, regente e professor. Em 1894 radica-se na França.

${ }^{25}$ Henrique Maximiliano Coelho Neto (1864-1934), escritor, político e professor.

${ }^{26}$ Ciríaco Cardoso (1846-1900), compositor português.

${ }^{27}$ Francisco Nunes (1875-1934), regente, clarinetista, professor e compositor.
} 
A carta segue, explicando os vícios criados, nos músicos e no público, pelas orquestras itinerantes das óperas, que simplificavam a instrumentação das obras.

Cernicchiaro registra também sua queixa sobre o destino profissional de jovens virtuoses:

Provando-o, que valha a história destes últimos tempos. Virtuoses eméritos de piano, de violino, etc., depois de um triunfo juvenil regular, são condenados ao exercício da música inferior, executada, sem convenções, em lugares públicos, para suprir as necessidades naturais da vida. (Cernicchiaro 1926, p. 612$)^{28}$

Que ecoa, por sua vez, uma queixa anterior de Roberto Kinsman Benjamin, publicada em 15 de outubro de 1886 na Gazeta de Notícias:

[...] não possuímos número suficiente de professores capazes de formar uma boa orquestra. A vida de um professor de orquestra no Rio é dura e para alguns mesmo cruel; quase todos com famílias que sustentar, manietados pelos contratos com os teatros, obrigados a executarem durante todo o ano música de um gênero trivial, forçados a assistir durante o dia a constantes ensaios de música de toda a espécie, menos de caráter elevado; se desejosos de tomar parte em algum concerto, tendo de caçar quem os substitua nos teatros - admira pouco que tenham escasso tempo e ainda menos inclinação para estudar, nem ocasião de alargar o conhecimento que têm das produções dos grandes mestres. Daí provém uma indiferença pelos intuitos mais elevados da arte musical, o meio interesse na música como meio de vida, e com isso aparece incontestavelmente uma negligência tanto de estilo como de forma, a qual, uma vez contraída, é difícil senão impossível desarraigar [...] (Benjamin apud Pereira, 2007, p. 47-48)

Também Oscar Guanabarino apresenta - ao fazer sua avaliação das condições de apresentação das óperas italianas no Rio - seus comentários sobre as práticas dos músicos de orquestra, em artigo de 26 de outubro de 1895:

Não é nem podia ser numerosa a sua orquestra; não só por motivos de ordem econômica como pela necessidade de manter certo equilíbrio com as forças de cena; assim como não foi fácil arregimentar todos os elementos

${ }^{28}$ Esta e todas as demais passagens em outros idiomas foram traduzidas por nós. 
orquestrais para o desempenho de grandes óperas, sabido, como é, que os nossos professores passam muitos meses sem se reunirem para a execução sinfônica e que vivem desanimados pelos teatros tocando enfadonhas partituras de mágicas e revistas.

\section{Músicos}

A biografia de vários compositores brasileiros é marcada pela multiplicidade de atividades e, muitas vezes, pelo trânsito em diferentes tipos de espaços musicais, ou até mesmo em outras áreas profissionais. Citamos anteriormente o caso de Villa-Lobos, que tocou em orquestras de cinema e de salão até se estabelecer profissionalmente, caso semelhante ao de Luciano Gallet. ${ }^{29}$

Parece ironia que a ópera apresentada no dia $1^{\circ}$ de janeiro de 1900 (comemorando, ainda que imprecisamente, o início do novo milênio) fosse Estela, de Assis Pacheco. ${ }^{30}$ Esse compositor cultivava a música como atividade paralela, sendo suas atividades principais a advocacia e o ministério público. O enredo de Estela trata, justamente, de um pobre compositor que vê sua filha, criança, morrer de fome enquanto as pessoas comemoram o Carnaval nas ruas.

Caso digno de nota é o de Henrique Alves de Mesquita que, após conquistar uma bolsa de estudos para continuar sua formação musical na Europa, abandona os estudos e, ao voltar ao Brasil, dedica-se à composição de operetas e peças leves. Trajetória que inspirou a Luiz Heitor a avaliação de que “[s]ua carreira não justificara a confiança que os círculos musicais do Império haviam depositado no jovem pensionista que em 1857 partia tão esperançoso para a Europa" (Azevedo, 1956, p. 70).

Os compositores "de escol" quando, por necessidade, se dedicavam aos gêneros mais populares, o faziam sob pseudônimo. Tal seria o caso de Homero Dornellas, ${ }^{31}$ violoncelista do Teatro Municipal, que assina a autoria do samba $\mathrm{Na}$ Pavuna em parceria com Almirante ${ }^{32}$ como Candoca da Anunciação, "[a]final, rapazes de boa família poderiam até gostar das coisas do sertão, mas não podiam

\footnotetext{
${ }^{29}$ Luciano Gallet (1893-1931), compositor, professor, pianista, regente e folclorista.

${ }^{30}$ Francisco de Assis Pacheco (1865-1937), compositor, teatrólogo, pianista, regente e crítico.

${ }^{31}$ Homero Dornelas (1901-1990), compositor, instrumentista e professor.

${ }^{32}$ Almirante, Henrique Foréis Domingues (1908-1980), cantor, compositor e radialista.
} 
cair no samba utilizando seus nomes de batismo" (Napolitano, 2007, p. 17). Tal seria o caso do próprio Nepomuceno, que assina uma opereta sob pseudônimo e que discutiremos mais adiante.

Abdon Milanez, ${ }^{33}$ diretor do Instituto Nacional de Música após a saída de Nepomuceno em 1916, era engenheiro de formação e dedicava-se à composição de danças de salão, operetas e revistas. Na crise que se segue à exoneração de Nepomuceno, sua condição de compositor de música ligeira será um dos alvos preferidos de seus detratores. ${ }^{34}$ Milanez chega a ensaiar a composição de obras "sérias", sem que isso consiga angariar-lhe o respeito de compositor erudito.

Outro episódio ocorrido no Instituto Nacional de Música, este, por sua vez, ligado à primeira saída de Nepomuceno da direção dessa casa, em 1903 é a discussão pelo corpo docente dessa casa sobre quais seriam os requisitos para que um membro da comunidade musical não pertencente ao Instituto fosse convidado para participar como membro honorário da Congregação, episódio que discutiremos adiante (ver Pereira, 2007).

Às mulheres, ainda que não fosse vedada, a opção por uma carreira musical não era muito típica. E não serão raros os casos como o de Noemia de 18 Oliveira, narrado por Cernicchiaro (1926, p. 480), “[t]ambém este talento emergente, poucos anos depois de seu triunfo, tomou marido, e, toda dedicada aos cuidados domésticos e ao afeto do consorte, aposentou-se da arte."

No intuito de criar condições para o desenvolvimento de um meio musical comparável com os dos principais centros europeus, Leopoldo Miguez tomou importantes iniciativas na organização do Instituto Nacional de Música - do qual foi primeiro diretor. Um documento eixo para entender essas ações é o relatório que apresenta ao Ministério da Justiça e Negócios Interiores analisando vários conservatórios de música europeus, dos quais toma exemplos para o Instituto carioca. Dentre as principais propostas encontra-se a criação dos cursos noturnos, que discutiremos mais adiante, e o estímulo ao estudo de instrumentos

\footnotetext{
33 Ábdon Milanez (1858-1927), compositor e teatrólogo.

${ }^{34}$ Para um minucioso relato e análise do episódio da demissão de Nepomuceno e dos choques entre os professores do Instituto Nacional de Música e Ábdon Milanez, ver o capítulo "Tempos de radicalização” em Pereira, 2007.
} 
de orquestra menos procurados com o propósito de formar corpos estáveis - coro e orquestra - destinados a tocar o repertório musical de concerto. ${ }^{35}$

\section{Instituições de ensino}

O Instituto Nacional de Música se constitui em uma instituição central para o exercício profissional da música no Rio de Janeiro, tanto como espaço de construção de um projeto musical, quanto como espaço de exercício de uma atividade profissional típica dos músicos, a docência.

O Instituto acabou congregando as vantagens materiais de um emprego com a dimensão simbólica de principal instituição do ensino musical no Brasil, o que o tornou um objetivo de carreira.

Carlos Gomes que, em carta de 1894 a Salvador Mendonça, evidencia a expectativa de uma nomeação para o então Conservatório de Música como reconhecimento de seus méritos pelo governo.

O Governo da nossa querida pátria parece me ter em consideração, mas até hoje não fui lembrado para um emprego qualquer no Conservatório de Música da Capital. Não tenho ânimo para pedir um lugar ao diretor daquele armazém de empregados; creio porém poder merecer (como abrigo) um lugar como os dos músicos portugueses que lá estão recebendo ordenados. (Gomes, 1936, p. 363) ${ }^{36}$

Esse reconhecimento viria, tarde, do Conservatório de Música de Belém do Pará.

Além do Instituto, outras escolas de música funcionavam no Rio de Janeiro: a Academia de Música de Cavallier Derbelly, a Escola de Música do Dr. Godofredo Leão Velloso, a Escola de Música Figueiredo-Roxo, o Ginásio de Música

\footnotetext{
${ }^{35}$ Ver Miguez, Leopoldo. Organização dos conservatórios de música na Europa. Relatório apresentado ao Ministério da Justiça e Negócios Interiores por Leopoldo Miguez, diretor do Instituto Nacional de Música do Rio de Janeiro, em desempenho da comissão de que foi encarregado em aviso do mesmo ministério de 16 de março de 1895. Rio de Janeiro: Imprensa Nacional, 1897. Ver nossa discussão do relatório em Vermes, 2004.

${ }^{36}$ Essa carta aparece citada em Azevedo, 1956, p. 87.
} 
da rua do Catete, o Instituto Benjamin Constant (antes Imperial Instituto dos Meninos Cegos) e a Nova Escola de Música de José Lima Coutinho. ${ }^{37}$

Para vários compositores assumir um posto no Instituto representava encontrar tranquilidade para compor. Tal parece ter sido o caso de Francisco Braga, Luciano Gallet e tantos outros.

\section{Alberto Nepomuceno no Rio de Janeiro}

Alberto Nepomuceno envolveu-se profissionalmente com a música ainda muito jovem. Filho de músico, ${ }^{38}$ teve de seu pai os primeiros ensinamentos musicais. Quando tinha oito anos, a família mudou-se de Fortaleza para Recife e foi lá que, depois da morte do pai em 1880, começou a trabalhar com música, lecionando piano e matérias teóricas.

Aos dezoito anos foi nomeado diretor do Club Carlos Gomes de Recife. ${ }^{39}$ Em 1884 a família retornou para Fortaleza e lá, no ano seguinte, foi enviada uma solicitação ao governo imperial para viabilizar uma viagem de estudos de Nepomuceno à Europa. O pedido foi negado. Nesse mesmo ano, 1885 , Nepomuceno transferiu-se para o Rio de Janeiro.

No Rio de Janeiro, ele integrou-se à vida musical da cidade, participando das atividades de relevantes instituições. Ministrou aulas de piano do Club Beethoven. Nesse período começou a compor de forma mais sistemática. ${ }^{40}$

Em 1887, Nepomuceno organizou um concerto com obras suas. O concerto, eu seu benefício, supriu uma iniciativa dupla: dar a conhecer suas obras ao público carioca e servir de fonte de subsídios para sua manutenção.

\footnotetext{
${ }^{37}$ Ver Cernicchiaro, 1926.

38 Seu pai, Victor Augusto Nepomuceno (1840-1880) era violinista, professor, mestre de banda e organista da Catedral de Fortaleza. Ver Corrêa, 1996. As informações biográficas de Nepomuceno são tomadas, salvo indicação contrária, desse catálogo e da Enciclopédia da Música Brasileira.

${ }_{39}$ Luiz Heitor refere-se a esse clube como "instituição que teve grande relevo na vida artística da província." (Azevedo, 1956, p. 161-62). Cernicchiaro o cita entre as sociedades musicais pernambucanas dignas de nota "uma vez que, além dos concertos que organizavam mensalmente, mantinham também escolas de música teoria e prática e orquestra" (Cernicchiaro, 1926, p. 551).

${ }^{40}$ Ver Vermes, 1996 e Corrêa, 1996.
} 
Tentou, novamente, obter apoio oficial para empreender uma viagem de estudos à Europa, o intento fracassou novamente. A partir daí contou com a ajuda de amigos - particularmente da família Bernardelli - e procurou reunir fundos para a viagem realizando recitais. Como parte dessa iniciativa, realizou uma turnê ao nordeste, acompanhado do violoncelista e amigo Frederico Nascimento.

Em 1888 Nepomuceno empreendeu sua viagem de estudos à Europa. A proclamação da república, no ano seguinte, garantiu-lhe, ainda que indiretamente, uma extensão da permanência nesse continente. Nepomuceno inscreveu-se no concurso para escolha do hino da república e, terceiro colocado, ganhou como prêmio uma bolsa que lhe permitiu permanecer lá até 1895 .

Em 1895 regressou ao Rio de Janeiro, já nomeado professor de órgão do Instituto Nacional de Música. ${ }^{41}$ A partir daí Nepomuceno empreendeu uma série de iniciativas nas quais podemos ler projetos em camadas superpostas: o trabalho que lhe assegura o sustento, a consolidação de seu nome como compositor e a criação/consolidação de um meio musical.

O período de sua volta da Europa até 1906, quando assume por segunda vez e de forma mais duradoura a direção do Instituto Nacional de Música, é um período extremamente produtivo de Nepomuceno como compositor. Ainda que seja difícil fazer uma ponderação objetiva sobre produtividade, observando a distribuição das obras ao longo da vida do compositor, é possível visualizar fases de adensamento de sua produção e associá-las às circunstâncias gerais de sua vida. Seus primeiros anos, antes da viagem à Europa são de um volume relativamente pequeno, seguidos de dois períodos extremamente produtivos: o período de sua permanência na Europa, o que é plenamente compreensível, já que lá estava para dedicar-se aos estudos e o período que se segue a sua chegada da Europa até 1906, a partir de quando sua produção se torna bastante esparsa. A grande responsabilidade assumida frente à direção do Instituto Nacional de Música e as consequências dessa atividade e exposição - batalhas estéticas, acadêmicas, políticas - se refletem em sua produção como compositor.

\footnotetext{
${ }^{41}$ A nomeação para o cargo ocorrera no ano anterior e motiva sua permanência por mais um ano na Europa, aprofundando o estudo do órgão em Paris com Alexandre Guilmant. Ver Pereira, 2007.
} 


\section{A inserção de Nepomuceno no meio musical carioca}

Em 1895, Nepomuceno se reinstalada definitivamente no Rio de Janeiro e, a partir daí, se desdobra em uma série de atividades. Uma das atividades mais centrais - e, como vimos acima, mais precoces - é a docência musical. Como mencionamos acima, ao voltar ao Brasil, o faz já nomeado professor de órgão do Instituto Nacional de Música, mais tarde desdobrado em professor de órgão e harmônio. Mas sua atividade como docente será mais ampla. No Instituto, Nepomuceno ocupará também a cadeira de Composição, ${ }^{42}$ além de se dedicar às aulas de piano particulares ${ }^{43}$ e às aulas de música em escolas privadas, que Nepomuceno menciona em sua correspondência. ${ }^{44}$

Mas, à parte das aulas, as atividades administrativas no Instituto Nacional de Música se tornariam o eixo da atividade profissional de Nepomuceno. Ele foi diretor do Instituto em duas ocasiões. A primeira, de curta duração, foi de 12 de julho de 1902 a 25 de maio de 1903 e a segunda foi de 22 de outubro de 1906 a 26 de outubro de 1916. Sua primeira posse provocou uma reação preocupada em Artur Azevedo: ${ }^{45}$

É uma iniquidade fazer com que um compositor do tamanho de Leopoldo Miguez ou do tamanho de Alberto Nepomuceno empregue na redação de um relatório, ou no exame de qualquer peça oficial, ou no deslindamento de uma intriga de repartição, as horas que poderia empregar na construção de um monumento da arte. (Azevedo apud Pereira, 2007, p. 141)

Ainda que compreensível, a reação de Azevedo encerra uma contradição no que diz respeito às possibilidades de sobrevivência do artista. O trabalho de

\footnotetext{
${ }^{42}$ Quadros minuciosos com a composição do quadro docente do Instituto Nacional de Música no período de 1890 a 1920 pode ser encontrado em Pereira, 2007.

${ }^{43}$ Nepomuceno em carta de 11 de novembro de 1916 a Luigi Maria Smido: "Tenho lições na Casa Vieira Machado às 5 as feiras, das 3 às $5 . "$

${ }^{44}$ Carta de Alberto Nepomuceno a Eivind Nepomuceno de 28 de abril de 1908: "As meninas estão no Colégio de Madame Lacombe, [...]. Eu vou ensinar solfejo e música teórica no Colégio delas [...]". Nepomuceno em carta de 02 de junho de 1918 a Luigi Maria Smido: "Durante a semana que começa amanhã estarei muito ocupado, pois tenho que perder dois dias inteiros no Colégio Sacré Coeur do Alto da Boavista, com um curso que tenho de piano e com um concurso de alunas. São dois dias de um trabalho consecutivo de 7 horas."

${ }^{45}$ Artur Azevedo (1855-1908), dramaturgo, poeta, contista e jornalista.
} 
Nepomuceno na direção do Instituto constituía - como continuação do trabalho de Miguez - um movimento no sentido de criar um ambiente musical. Fazer apresentar suas obras, editar suas partituras constituíam iniciativas que possibilitariam que sua obra fosse conhecida e apreciada, mas era difícil contar com isso como base para a sobrevivência. Seria necessário criar corpos estáveis orquestra e coro - e uma temporada regular de concertos como parte de um projeto mais amplo cujo propósito seria consolidar a atividade musical erudita no Rio de Janeiro. Mas, como vimos acima, a instabilidade dessas iniciativas impedia que um músico fizesse carreira dedicando-se exclusivamente ao repertório sinfônico. Uma avaliação e uma proposta de solução para sanar esse problema já haviam sido apresentadas por Leopoldo Miguez em seu relatório sobre os conservatórios europeus: ${ }^{46}$ a criação dos cursos noturnos. Esses cursos seriam destinados à formação de músicos profissionais, dando acesso ao Instituto a pessoas impossibilitadas de frequentar as aulas diurnas por precisarem trabalhar. Coube a Nepomuceno implementar essa iniciativa, que seria extinta pelo próximo diretor do Instituto, Henrique Oswald. ${ }^{47}$

A preocupação de Nepomuceno como o exercício profissional da música fica evidente em outro episódio de sua história no Instituto. O pedido de exoneração da direção do Instituto que apresentou em 1903 teve como eixo a proposta de indicação do crítico José Rodrigues Barbosa para membro honorário da congregação do Instituto. A exigência para tornar-se elegível para essa indicação era tratar-se de um "artista notável" que não compusesse os quadros da instituição. A discussão sobre a adequação dessa indicação dividiu o corpo docente e extrapolou o âmbito do Instituto. Pereira (2007, p. 149) sintetiza os argumentos de Nepomuceno contra a indicação de Barbosa:

Nepomuceno defende também a qualidade de um produto desenvolvido pelo artista, pois profissional é precisamente aquele que por suas qualidades técnicas e estéticas é reconhecido por seus pares, o que o habilita a exercer a

\footnotetext{
${ }^{46}$ Ver Miguez, Leopoldo. Organização dos conservatórios de música na Europa. Relatório apresentado ao Ministério da Justiça e Negócios Interiores por Leopoldo Miguez, diretor do Instituto Nacional de Música do Rio de Janeiro, em desempenho da comissão de que foi encarregado em aviso do mesmo ministério de 16 de março de 1895. Rio de Janeiro: Imprensa Nacional, 1897. Ver também Vermes, 2004.

47 Sobre a criação dos cursos noturnos ver Pereira, 2002. e Pereira, 2007.
} 
profissão seja como solista, seja como integrante de orquestra ou outros conjuntos, ou ainda, como compositor ou regente. O amador raramente alcança tal situação. Indo além. Nepomuceno distingue ainda uma linha divisória entre o trabalho do músico e o do crítico. Embora reconhecesse a competência de Rodrigues Barbosa como crítico, ela de nada lhe valeria para os efeitos da nomeação para o cargo, pois o que contava era ser músico prático e notável, ou seja, reconhecido, e não apenas desenvolver profissão afim. Está entendido, no ofício de Nepomuceno ao ministro, que crítico não é artista.

Ficará evidente também, na ocasião do segundo pedido de exoneração do cargo de diretor do Instituto em 1916 e na crise que se sucede, por ocasião da indicação de Abdon Milanez para a direção, que os limites, ainda que tácitos, eram rigorosos. Um compositor de danças de salão não era um par.

Outra faceta da atividade profissional musical de Nepomuceno - e a mais reconhecida talvez - é a de compositor. Ele procurou consolidar sua posição como compositor produzindo concertos de suas obras. Alguns desses concertos foram especialmente significativos, dos quais destacamos os concertos de 1895 e 1897. No primeiro, realizado no Instituto Nacional de Música, Nepomuceno se apresentou como compositor, pianista e organista. No segundo, também no Instituto, apresentou primeiras audições de obras sinfônicas.

O Instituto Nacional de Música tornou-se, pelo menos até sua mudança ao novo edifício em 1910, num dos espaços preferenciais para a realização de concertos. Outras salas para esse tipo de evento eram o Teatro Lírico, o Cassino Fluminense, o Teatro São Pedro de Alcântara, o Salão do Jornal do Commercio e o Teatro Municipal, formando um circuito paralelo - ainda que com algumas superposições - ao dos espetáculos musicais mais populares.

É difícil medir o bom resultado de tais concertos quanto a suas consequências estéticas, mas constituíam uma fonte de renda bastante instável, sujeita à "concorrência" de vários outros eventos de maior apelo. É o que indica Luís de Castro no texto publicado na Gazeta de Notícias tratando do concerto com obras de Nepomuceno de 1897:

Não conseguiste, é certo, encher o salão do Instituto de Música, nem tirar lucro material do teu insano e árduo trabalho. É que tinhas ontem dois temíveis concorrentes: uma tourada especial e uma corrida de 
cavalos igualmente especial, e bem sabes que, para o desenvolvimento desta nossa terra, os touros são indispensáveis, como indispensável é melhorar a raça cavalar, fazendo-a correr e vendendo poules. (Castro apud Pereira, 2007, p. 128)

A estreia de Nepomuceno na ópera se deu em 1898, com Ártemis, no Teatro São Pedro de Alcântara, numa iniciativa do Centro Artístico. Mas verdadeiro acontecimento nesse sentido foi a estreia de $\mathrm{Abul}$, projeto de grande envergadura e de projeção internacional. Conquistou um grande sucesso em Buenos Aires (1913), mas, em meio a uma série de desentendimentos com o empresário contratado para a produção, fracassa em Roma (1915). No entusiasmo após o sucesso da estreia na Argentina, Nepomuceno entendia que essa poderia ser a porta de entrada para outros músicos brasileiros naquele país.

Outra iniciativa no sentido da consolidação de sua carreira como compositor foram os esforços para publicação de suas obras, no Brasil e no exterior. Uma transação desse tipo ficou registrada na troca de correspondência entre Nepomuceno e a editora norte-americana G. Schirmer. ${ }^{48}$ Das várias obras que Nepomuceno ofereceu para publicação, a editora se interessou pela publicação do Noturno para a mão esquerda. Nepomuceno se propôs então a pagar pela edição e recebeu da editora uma negativa:

A proposta que nos faz, ou seja, de pagar pela impressão e pela gravação das peças, e que as edições subsequentes sejam impressas por nossa conta. Nós não publicamos nada por conta dos compositores, pois todas as obras mencionadas em nossos catálogos são ou nossa propriedade exclusiva, ou trabalhos editados com base em contrato de tanto por cento e em nenhum caso permitimos que os gastos de impressão e gravação sejam pagos pelos compositores. $^{49}$

A editora não cede à proposta do compositor, seja de liberar a publicação do noturno desde que outras obras fossem publicadas, ou de pagar ele mesmo pela edição, e vai direto ao ponto: "se o Sr. se empenhar em que a aceitação da

\footnotetext{
${ }^{48}$ Discutimos o intercâmbio entre Nepomuceno e a Editora Schirmer em nossa dissertação de mestrado, ver Vermes, 1996. Ver também Pereira, 2007. p. 235-37.

49 Essa carta é parte do acervo da família Nepomuceno e o acesso a ela nos foi generosamente permitido por Sergio Alvim Corrêa, neto do compositor.
} 
mesma seja condicional, sentimos muitíssimo em ver-nos obrigados a prescindir desse prazer [de publicar o noturno]".

No intercâmbio que se segue a editora insiste em dois pontos: no projeto de ver adotadas suas publicações no Instituto, para o que gostaria de contar com o auxílio do prestígio de Nepomuceno, e na recusa de editar obras que não tenham um potencial mais vasto de público. As obras enviadas por Nepomuceno são demasiado difíceis "para poder tornar-se populares neste país [EUA]". Insistem nos parágrafos seguintes no interesse quem têm em obras novas, desde que não sejam difíceis demais para o público em geral.

A edição do Noturno para a mão esquerda sai, finalmente, em 1917. após alguns problemas.

Esse intercâmbio com a Schirmer não foi o único contato de Nepomuceno com editoras estrangeiras. Há uma série de cartas de Nepomuceno à editora C.G. Röder de Leipzig, ${ }^{50}$ tratando da publicação de obras suas, particularmente canções. Tais edições seriam custeadas pelo próprio compositor, o que é evidenciado pela correspondência enviada a um banco alemão solicitando a transferência de valores para essa editora. ${ }^{51}$ Nepomuceno também serve de 26 intermediário entre Leopoldo Miguez e a C.G. Röder para a edição de sua ópera Os Saldunes, a pedido do compositor. ${ }^{52}$

Outro desdobramento das atividades de Nepomuceno é a regência. Como regente participou de iniciativas importantes: a direção da Associação de Concertos Populares, frente à qual regeu entre 1896 e 1897 duas séries de concertos, totalizando dezesseis espetáculos, ${ }^{53}$ todos realizados no Teatro Lírico.

Outra série importante de concertos organizados por Nepomuceno foram aqueles apresentados durante a Exposição Nacional de 1908, celebrando o centenário de abertura dos portos às nações amigas. Parte dos concertos foi também regida por ele, responsabilidade dividida com Francisco Braga, Assis

\footnotetext{
${ }^{50}$ Cartas datadas de 04 jul. 1901, 23 ago. 1903, 06 dez. 1903, 10 mai. 1904, 26 fev. 1905 e 05 jul. 1908. (Acervo da DIMAS-BN)

${ }^{51}$ Cartas datadas de 18 abr. 1906 e 16 dez. 1906. (Acervo da DIMAS-BN)

${ }^{52}$ Cartas datadas de 15 mai. 1901, 06 jun. 1901, 04 jul. 1901, 05 jul. 1901, 04 ago. 1901. 02 set. 1901. (Acervo da DIMAS-BN)

${ }^{53}$ Para a programação completa dos concertos, ver Corrêa, 1996.
} 
Pacheco, Agostinho Gouvêa e Francisco Nunes Jr.. ${ }^{54}$ Mais tarde estaria também à frente da Sociedade de Concertos Sinfônicos, que deixou em 1919, já com a saúde debilitada.

Dividido entre tantas atividades, é frequente na correspondência de Nepomuceno encontrar alusões a quanto está atarefado e cansado e a preocupação em assegurar os meios de sobrevivência é uma questão recorrente.

Nepomuceno casou-se na Europa com a pianista norueguesa Walborg Bang, com quem teve quatro filhos. O mais velho, Eivind, foi mandado para estudar na Suíça e a correspondência entre ele e o pai no seu período de permanência lá, assim como as cartas trocadas com as filhas, Astrid e Sigrid, nas temporadas em que a família mantinha residência em Petrópolis e Nepomuceno “descia” ao Rio para cumprir suas obrigações profissionais ou se encontrava viajando, testemunham suas preocupações. Mas já em agosto de 1895, dizia em carta a Eliseu Visconti: ${ }^{5}$ "Mas é como te digo não tenho tempo. Conservatório de Pernambuco, mudança, Concerto, lições - tudo junto é demais." e ao mesmo Visconti em novembro do mesmo ano: "Muito tens esperado por cartas minhas e em vão. Não penses que me esqueci de ti. Não. Tenho estado muito ocupado."

Em carta a Eivind, de 17 de março de 1908, quando o filho parece estar desgostoso como a escola em que estuda e ameaça fugir: "Provavelmente fazes e dizes isto por não te lembrares ou ignorares que eu passo aqui por tantas provações morais, que os meus sofrimentos quer físicos, quer morais são inúmeros e muito fortes. Eu faço o mais que posso para dar-te uma educação superior [...]" e mais adiante na mesma carta

[...] para o ano de 1909 irei buscar-te. Este ano é absolutamente impossível. Agora mesmo sou avisado que a direção geral da Exposição no Rio quer que eu dirija uma série de 8 concertos. Isto dará um lucro de uns 5 contos de réis que perderei se for à Europa. Eu sei que pelas despesas excessivas que tenho tido preciso um momento de calma para refazer as finanças. Não devo nada, felizmente, mas não tenho reservas, e para viajar torna-se necessário possuí-las.

\footnotetext{
${ }^{54}$ Para a programação completa dos concertos, ver Corrêa, 1996. Ver também Goldberg, 2006.

${ }^{55}$ Eliseu Visconti (1866-1944), pintor ítalo-brasileiro.
} 
Nepomuceno, como alguém que construíra uma carreira à base de grandes esforços, vivera sempre - salvo quando muito jovem, antes da transferência ao Rio de Janeiro - do trabalho com a música e tinha, por isso mesmo, um senso muito claro da necessidade de condições estáveis e dignas.

Duas cartas de Nepomuceno de $1901^{56}$ mostram que ele chegou a cogitar a possibilidade de trabalhar nos Estados Unidos. Dirigidas a F. Ziegfeld, ${ }^{57}$ diretor do Chicago Musical College, enumeram sinteticamente as competências de Nepomuceno, que poderia ensinar composição, piano, órgão e prática de orquestra, e de sua mulher, Walborg Bang, professora de piano, e chegam a mencionar especificidades de contrato. O projeto, como sabemos, não foi levado a cabo. Certamente a nomeação de Nepomuceno para a direção do Instituto Nacional de Música no ano seguinte deve ter proporcionado um encaminhamento ao seu estabelecimento profissional que provavelmente pesou para que as coisas tomassem esse rumo.

Outro episódio digno de destaque é a composição, em 1911, de uma opereta por Nepomuceno, em parceria com Luís de Castro, ambos utilizando pseudônimos: João Valdez o primeiro e Eduardo Rivas o segundo. O fato dos

28 autores aparecerem escondidos atrás de pseudônimos sugere a medida em que esse exercício "do lado de lá" poderia ser comprometedor para figuras tão em evidência no universo da cultura erudita. Pode ser pista também da medida em que o mundo dos espetáculos populares poderia se configurar como uma alternativa de trabalho que ajudasse a assegurar rendimentos.

\section{Considerações Finais}

Profissionais, amadores, diletantes. Compositores de música erudita ou de música de salão. Músicos com formação acadêmica e sem ela. Músicos que tocavam na sinfônica ou nas orquestrinhas de salão. A formação, as escolhas estéticas, a fonte

\footnotetext{
${ }^{56}$ Ambas as cartas foram redigidas em alemão. A primeira é datada de 04 mar. 1901 e a segunda de 07 mai. 1901 e fazem parte do acervo da família do compositor.

57 Florenz Ziegfeld, Sr., diretor do Chicago Musical College e pai de Florenz Ziegfeld, Jr. (1867-1932), famoso produtor da Broadway.
} 
de recursos para sobrevivência, os espaços de atuação são categorias que, isoladamente, sugerem uma estrutura claramente estratificada. Mas, observando de perto, é possível perceber que, no Rio de Janeiro do período que tratamos, há trânsitos e multiplicidades de papéis que impedem uma hierarquização clara e rígida.

Nepomuceno assume uma missão importante no sentido de ajudar a criar as condições para um exercício profissional da música de concerto, "na construção da consciência da necessária profissionalização do músico, formada em senso de oportunidade e visão prospectiva" (Pereira, 2002, p. 7). Num certo sentido, as atividades de Nepomuceno - e não só na direção do Instituto Nacional de Música - representam uma continuação das iniciativas de Leopoldo Miguez, com quem partilha convicções e a quem sucede nessa função. Mas são também uma continuidade de iniciativas que podemos identificar muito nitidamente já nas atividades de Francisco Manuel da Silva. Não só pela linha direta que se pode estabelecer entre o Conservatório e o Instituto Nacional de Música, mas também pela multiplicidade de papéis com que procuram assegurar as condições para a formação e o exercício profissional dos músicos. Isso só é plenamente compreensível considerando a superposição e o imbricamento dos dois mundos: um mundo que se via como herdeiro e continuador da grande tradição musical erudita europeia e que parece sempre estar em estado de fundação e o que se fazia aqui, "neste país de botocudos", conforme escrevia Miguez em carta a Carlos de Mesquita de $1883 .^{58}$

Mas, se de um lado as iniciativas de Nepomuceno correspondem a uma continuação dessa tradição, elas também se configuram em inovação, na medida em que são resposta às novas condições sociais, econômicas e culturais da capital de um país que passava por numerosas, profundas e rápidas transformações.

Conscientemente ou não, as iniciativas de Nepomuceno, ações de exercício profissional e, ao mesmo tempo, de criação de um universo profissional, continuação de uma vertente e resposta às novas condições que se apresentavam, constituem também uma reação ao mundo em que vivia e que parece se desdobrar em dois mundos musicais paralelos, que tomam conhecimento e, ao mesmo tempo, omitem um ao outro.

\footnotetext{
${ }^{58}$ Carta de Leopoldo Miguez a Carlos de Mesquita, datada de 30 nov. 1883 (acervo da DIMAS-BN).
} 
Parece-nos questão de fundamental importância para reflexão notar que a sobrevivência dos músicos eruditos no período que aqui tratamos seja tão fortemente dependente da docência musical, ao passo que o fazer musical seja a garantia de sustento dos músicos dedicados a gêneros mais populares, como a opereta e o teatro de revista.

No necrológio que Guanabarino escreveu por ocasião da morte de Nepomuceno e que citamos no início deste texto, o crítico acusa o músico de se dividir em vários papéis diferentes que Ihe impediam de atingir a excelência em qualquer um deles. No mesmo artigo, mais adiante, ao falar da ópera $A b u l$, diz que Nepomuceno "pensava erradamente que as óperas devem ser escritas para os artistas e não para o público, em geral" (Guanabarino, 1920), mas, entrado o século XX ser compositor erudito não implicava, ao menos em certa medida, ser um "compositor para compositores"?

A multiplicidade das atividades de Nepomuceno, que procuramos aqui relacionar com o ambiente do exercício profissional da música no Rio de Janeiro entre 1895 e 1920, é uma resposta necessária à conciliação da atividade musical como meio de sustento dentro das condições dadas nesse momento e a corajosa posta em 30 prática de um projeto transformador da música e do meio musical carioca.

\section{Referências}

AZEVEDO, Luiz Heitor Corrêa de Azevedo. 150 anos de música no Brasil (18001950). Rio de Janeiro: José Olympio, 1956.

CERNICCHIARO, Vincenzo. Storia della Musica nel Brasile: dai tempi coloniali sino ai nostri giorni (1549-1925). Milano: Fratelli Riccioni, 1926.

CORRÊA, Sérgio Alvim. Alberto Nepomuceno: catálogo geral. 2. ed. Rio de Janeiro: Funarte, 1996.

Enciclopédia da música brasileira: popular, erudita e folclórica. 2. ed. São Paulo: Art / Publifolha, 1998.

GOLDBERG, Guilherme Duro. Concertos da Exposição Nacional da Praia Vermelha (1908): ponta de lança para a modernidade musical no Brasil. In: Congresso da Associação Nacional de Pesquisa e Pós-Graduação em Música, 16, 2006. Brasília. Anais... Brasília: UnB, 2006.

GOMES, Carlos. Cartas diversas - Cartas a Manoel José de Souza Guimarães. Revista Brasileira de Música, Rio de Janeiro, v. III, p. 363, 1936. 
GUANABARINO, Oscar. Artes e Artistas - Teatro Lírico. O Paiz, Rio de Janeiro, 26 out. 1895.

. Pelo mundo das artes. Jornal do Commercio, Rio de Janeiro, 19 out. 1920.

MACHADO, Cacá. "Batuque: mediadores culturais do final do século XIX". In: MORAES, José Geraldo Vinci de; SALIBA, Elias Thomé (Org.). História e Música no Brasil. São Paulo: Alameda, 2010.

MIGUEZ, Leopoldo. Organização dos conservatórios de música na Europa. Relatório apresentado ao Ministério da Justiça e Negócios Interiores por Leopoldo Miguez, diretor do Instituto Nacional de Música do Rio de Janeiro, em desempenho da comissão de que foi encarregado em aviso do mesmo ministério de 16 de março de 1895. Rio de Janeiro: Imprensa Nacional, 1897.

NAPOLITANO, Marcos. A síncope das idéias: a questão da tradição na música popular brasileira. São Paulo: Editora Fundação Perseu Abramo, 2007.

PEREIRA, Avelino Romero. Alberto Nepomuceno: música, educação e trabalho. Brasiliana, Rio de Janeiro, n. 10, p. 2-8, jan. 2002.

- Música, sociedade e política: Alberto Nepomuceno e a República Musical. Rio de Janeiro: Editora UFRJ, 2007.

"Teatros e música”. Jornal do Commercio, Rio de Janeiro, 16 mar. 1895.

VERMES, Mónica. Ser brasileiro no final do século XIX: música e idéias em torno do Instituto Nacional de Música. In: Encontro de Musicologia História Musicologia Histórica Brasileira em Tempos de Transdisciplinaridade, 7, 2006. Anais... Juiz de Fora: Centro Cultural Pró-Música, 2006. p. 112-121.

. Por uma renovação do ambiente musical brasileiro: o relatório de Leopoldo Miguez e os conservatórios europeus. Revista Eletrônica de Musicologia, Curitiba, v. VIII, dez. 2004. Disponível online em <http://www.rem.ufpr.br/ _REM/REMv8/miguez.html>.

A produção para piano a duas mãos de Alberto Nepomuceno: características gerais e proposta de um novo catálogo. Revista Música, São Paulo, v. 7, n. 1/2, p. 59-91, mai./nov. 1996.

. Alberto Nepomuceno e a criação de uma música brasileira: evidências em sua obra para piano. São Paulo, 1996. Dissertação (Mestrado) - Instituto de Artes, Unesp, São Paulo. 1996.

\section{Correspondência}

- Leopoldo Miguez a Carlos de Mesquita, 30 nov. 1883 (DIMAS-BN)

- Alberto Nepomuceno a Eliseu Visconti, 15 ago. 1895 (Acervo Família Alberto Nepomuceno - AFAN)

- Alberto Nepomuceno a Eliseu Visconti, 02 nov. 1895 (AFAN)

- Alberto Nepomuceno a F. Ziegfeld, 04 mar. 1901 (AFAN)

- Alberto Nepomuceno a F. Ziegfeld, 07 mai. 1901 (AFAN) 
- Alberto Nepomuceno a Eivind Nepomuceno, 28 abr. 1908 (Acervo Família Alberto Nepomuceno - AFAN)

- G. Schirmer (Inc) a Alberto Nepomuceno, 05 jan. 1915 (AFAN)

- G. Schirmer (Inc) a Alberto Nepomuceno, 03 set. 1915 (AFAN)

- G. Schirmer (Inc) a Alberto Nepomuceno, 09 out. 1915 (AFAN)

- G. Schirmer (Inc) a Alberto Nepomuceno, 12 nov. 1915 (AFAN)

- G. Schirmer (Inc) a Alberto Nepomuceno, 04 abr. 1916 (AFAN)

- Alberto Nepomuceno a Luigi Maria Smido, 11 nov. 1916 (AFAN)

- G. Schirmer (Inc) a Alberto Nepomuceno, 26 abr. 1917 (AFAN)

- G. Schirmer (Inc) a Alberto Nepomuceno, 15 mar. 1918 (AFAN)

- Alberto Nepomuceno a Luigi Maria Smido, 02 jun. 1918 (AFAN)

- Sílvio Deolindo Fróis a Alberto Nepomuceno, 20 de agosto de 1919 (AFAN)

\section{Sites}

<http://WwW.ctac.gov.br/centrohistorico/apresentacao.asp acessado em set. 2010>.

32 E-mail: mvermes@uol.com.br

Artigo recebido e aprovado em 20 de setembro de 2010 